history of epilepsy. Brain imaging studies were normal. Two showed paroxysmal EEG abnormalities with intermittent photic stimulation. All 4 with cartoon-evoked seizures had a $3-\mathrm{Hz}$ spike-and-wave photoparoxysmal response (PPR) when exposed to the blue/red colored cartoon frames at 6 and $12 \mathrm{~Hz}$ flicker rates, and less frequently, only at $12 \mathrm{~Hz}$ flicker, with a monochromatic gray/black version of the cartoon. In contrast, 2 boys with TV game epilepsy were unaffected by the cartoon. (Tobimatsu S, Zhang YM, Tomoda Y, Mitsudome A, Kato M. Chromatic sensitive epilepsy: a variant of photosensitive epilepsy. Ann Neurol June 1999;45:790-793). (Respond: Dr Tobimatsu, Department of Clinical Neurophysiology, Neurological Institute, Faculty of Medicine, Kyushu University, 3-1-1 Maidashi, Higashi-Ku, Fukoka 812-8582, Japan).

COMMENT. TV producers of children's programs need to be alerted not only to the adverse effects of violence but also to the color content of their cartoons. Factors responsible for precipitating photosensitive epileptic seizures include light, pattern, stimulus frequency, and, in addition, the blue/red colors. Testing for chromatic sensitivity should be added to the list of activating procedures during EEG recordings in children with suspected photosensitive epilepsy.

\title{
TOPIRAMATE IN LENNOX-GASTAUT SYNDROME
}

The efficacy and safety of topiramate as adjunctive therapy for LennoxGastaut syndrome were studied in an 11-week multicenter, double-blind, placebocontrolled trial involving 98 patients, 1-30 years of age, and reported from the New Jersey-Robert Wood Johnson Medical School, New Brunswick, NJ. A greater than $50 \%$ reduction in drop attacks and tonic-clonic seizures was obtained in one third, and parental global evaluations indicated a reduction in seizure severity. Adverse events occurring with greater frequency in the topiramate patients than in controls included somnolence, anorexia, nervousness, behavioral problems, fatigue, dizziness, and weight loss, but none caused treatment to be completely withdrawn. (Sachdeo RC, Glauser TA, Ritter F et al, and Topiramate YL Study Group. A double-blind, randomized trial of topiramate in Lennox-Gastaut syndrome. Neurology June 1999;52:1882-1887). (Reprints: Dr Rajesh C Sachdeo, University of Medicine and Dentistry of New Jersey-Robert Wood Johnson Medical School, 97 Paterson St, Room 118, New Brunswick, NJ 08903).

COMMENT. Topiramate may be effective as adjunctive therapy in LennoxGastaut syndome.

Topiramate pharmacokinetics and tolerability were studied in 18 children, 4-17 years of age, at the Epilepsy Care Center, Chesterfield, MO, using graded doses from $1 \mathrm{mg} / \mathrm{kg} /$ day, increasing weekly to $9 \mathrm{mg} / \mathrm{kg} /$ day or $800 \mathrm{mg} /$ day at the 4th week. (Rosenfeld WE et al. Pediatr Neurol May 1999;20:339-344). Oral plasma clearance was independent of dose, and plasma concentrations were proportional to the dose. Topiramate clearance was $50 \%$ greater than that in adults, and higher in children receiving enzyme-inducing antiepileptic drugs. Steady-state plasma topiramate concentrations are $33 \%$ lower in pediatric than in adult patients, for the same $\mathrm{mg} / \mathrm{kg}$ dose. Adverse events occurring in $39 \%$ to $17 \%$ of patients included anorexia, fatigue, nervousness, and attention problems.

\section{RISK OF STEVENS-JOHNSON SYNDROME WITH AED THERAPY}

The role of antiepileptic drugs in Stevens-Johnson syndrome (SJS) and toxic epidermal necrolysis (TEN) was evaluated in a case-control study in Europe and reported from Mannheim, Germany. Of 352 cases of SJS/TEN, 73 (21\%) had received antiepileptic drugs, and of the cases associated with AEDs, 8 (11\%) died. 